\title{
Evaluation of final-year dental students concerning therapeutic decision making for proximal caries
}

\section{Juliane Bervian(a) \\ Maximiano Ferreira Tovo(b) \\ Carlos Alberto Feldens ${ }^{(c)}$ \\ Larissa Corrêa Brusco(d) \\ Francinne Miranda da Rosa ${ }^{(\mathrm{e})}$}

(a) MSc, Professor, School of Speech and Language Therapy, University of Passo Fundo, Passo Fundo, RS, Brazil.

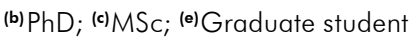
- Department of Pediatric Dentistry, School of Dentistry, Lutheran University of Brazil, Canoas, RS, Brazil.

(d) MSc, Private Practice.

\begin{abstract}
This cross-sectional study aimed to determine the radiographic criteria used by final-year dental students when defining the need for restorative treatment for proximal caries, as well as investigating potentially associated factors in this therapeutic decision. A questionnaire with two schematic diagrams presenting five levels of proximal lesion penetration was administered to students attending the six private and three public dental schools in the state of Rio Grande do Sul, Southern Brazil. Absolute and relative frequencies were described and inferential statistics involving Chi-square and McNemar tests and simple logistic regression were carried out to assess variations in therapeutic decisions related to patient dentition (deciduous/permanent) and gender, age and dental school (public/private). Of the 346 dental students assessed, $28.6 \%(99 / 346)$ indicated restorative treatment for lesions restricted to the enamel in deciduous teeth and $38.2 \%$ (132/346) indicated the same for permanent teeth, revealing a statistically significant difference $(p=0.001)$. Student gender and age were not associated with the therapeutic decision; however, a significant difference between dental schools was found when comparing restorative criteria in deciduous $(\mathrm{p}<0.001)$ and permanent molars $(\mathrm{p}<0.001)$. The odds of restorative decision in permanent teeth when the caries lesion was restricted to the enamel was $72 \%$ higher for students graduating from private schools compared to public schools (Odds Ratio: 1.72; 95\% Confidence Interval: 1.03-2.90). These data demonstrate a large variation between the therapeutic decisions regarding proximal caries reported by final-year dental students and suggest that deep reflection is needed on the part of faculty in order to provide an evidence-based education.
\end{abstract}

Descriptors: Dental caries; Diagnosis; Radiography.
Corresponding author:

Maximiano Ferreira Tovo

Rua Visconde do Herval, 850, Apto. 604, Menino de Deus

Porto Alegre - RS - Brazil

CEP: 90130-150

E-mail:maxftovo@terra.com.br
Received for publication on Jun 29, 2007

Accepted for publication on Nov 08, 2007 


\section{Introduction}

For many years, therapeutic decision making in relation to proximal caries lesions was based on the radiographic aspects of the same. The presence of radiolucency, regardless of its extension, inexorably required a surgical restorative process.

Following the clinical advances and the new knowledge acquired on the events that lead to a demineralization process, the related literature has contributed to basing decisions on sustainable evidence. ${ }^{1-3}$ Even though several paradigmatic publications exist regarding this subject, some studies reveal that, when using the radiographic criteria, decisions appear to reflect the understanding of inevitable and rapid progress of caries lesions. ${ }^{1,2,4}$

Comprehension of this process by dental professors and professionals has been the object of several studies. The foundation and evolution of the decisions made by final-year students has instigated new research. ${ }^{4-6}$

Thus, the objective of the present study was to evaluate the therapeutic decision making of finalyear dental students from universities in Rio Grande do Sul, when approaching radiographic images of proximal caries lesions in the deciduous and permanent dentitions. Associations between the decision made and the dental school, gender and age of the student were also investigated.

\section{Material and Methods}

This cross-sectional study was approved by the Ethics Committee for Research on Humans of the Lutheran University of Brazil (protocol $\mathrm{n}$. 025/2002). The dental schools and students authorized the realization of this study by signing a term of free informed consent.

\section{Study population}

The study population was composed of finalyear dental students enrolled in six private and three public schools in the state of Rio Grande do Sul. Final-year students were defined as those who were studying in the final semester or year of undergraduate school who, following the proposed curriculum, had concluded the disciplines Pediatric Dentistry I and II and Radiology.
Calculations regarding the sample size indicated that interviewing 309 final-year students was required, using the following parameters: $95 \%$ confidence level and power of $80 \%$ to detect a $60 \%$ difference in the restorative treatment decision criteria between students from public (unexposed) and private (exposed) institutions (exposed and unexposed ratio of $5: 2$, the frequency of the outcome unexposed being $20 \%$, which was detected in a pilot study). However, sample selection was abandoned after considering the logistical possibility of collecting data from the entire final-year population.

\section{Questionnaire}

A questionnaire to determine age, gender and dental school attended by the final-year students was applied (Figure 1). Next, the students were presented to two schematic diagrams presenting five different levels of radiographic penetration in proximal caries lesions, related to two patients: a 6-year-old presenting $\mathrm{dmft}=1$; and a 15 -year-old presenting DMFT $=1$. The students were required to indicate at what level they would opt for restorative treatment in deciduous and permanent dentitions. ${ }^{5,7,8}$

\section{Data analysis}

Initially, the absolute and relative frequencies of the restorative decisions made by the students were described. The outcome was dichotomized, so the five levels of radiographic penetration of the lesions in both dentitions were grouped into two categories: lesions penetrating up to the dentino-enamel junction (DEJ) and lesions penetrating from the external third of the dentine onwards.

To assess whether any difference existed in those frequencies between gender, age groups (in terciles) and dental schools, the Chi square test was performed, with a significance level set at $\mathrm{p}<0.05$. To compare the restorative treatment criteria between public and private dental schools, simple logistic regression was used. This procedure provides odds ratios (OR), which indicate how much greater the probability of a certain outcome is in those exposed than in those unexposed. ${ }^{9}$ Adjustment for student gender and age was not performed because these variables did not present the conditions postulated 


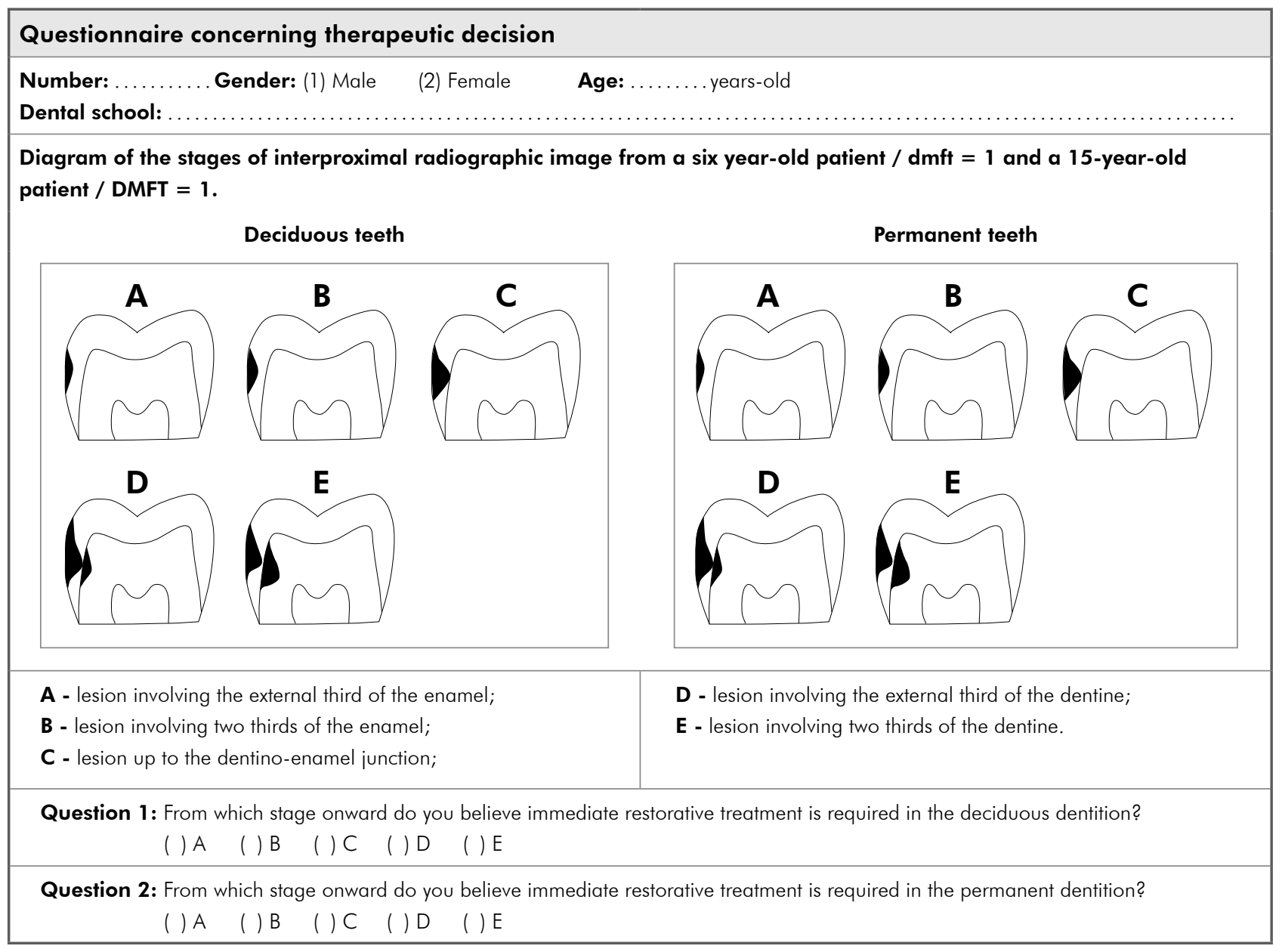

Figure 1 - Questionnaire administered to the final-year dental students.

for confounding factors ${ }^{9}$ in this study. Analyses were performed using the Epi-Info (version 3.3.2, CDC, Atlanta, GA, USA) and SPSS (version 13.0, SPSS Inc., Chicago, IL, USA) software.

\section{Results}

Of a total of 355 final-year students, the replies of 346 (response rate of $97.5 \%$ ) were analyzed, including $38.2 \%(\mathrm{n}=132)$ males and $61.8 \%(\mathrm{n}=214)$ females. Age varied between 20 and 43 years, with a mean (standard deviation) of 24.5 (3.8) years and median (Q25-Q75) value of $23(22-25)$ years. The number of final-year students per dental school varied between 26 and 66 .

The replies of the 346 students regarding the stage at which restorative treatment should occur in the deciduous dentition were distributed as fol- lows: external $1 / 3$ of enamel: $n=7(2.0 \%) ; 2 / 3$ of enamel: $\mathrm{n}=14(4 \%)$; DEJ: $\mathrm{n}=78$ (22.5\%); external $1 / 3$ of dentine: $n=172(49.7 \%) ; 2 / 3$ of dentine: $\mathrm{n}=75(21.7 \%)$. In the permanent dentition the decisions were as follows: external $1 / 3$ of enamel: $\mathrm{n}=9$ $(2.6 \%) ; 2 / 3$ of enamel: $n=23(6.6 \%) ;$ DEJ: $n=100$ (28.9\%); external $1 / 3$ of dentine: $\mathrm{n}=140(40.5 \%)$; $2 / 3$ of dentine: $\mathrm{n}=74(21.4 \%)$.

Considering the dichotomized outcome, observation showed that 181 final-year students $(52.3 \%)$ indicated restorative treatment in both dentitions only when the lesion reached the dentine, while 66 $(19.1 \%)$ suggested restorative treatment in both dentitions for lesions extending up to the DEJ (Table 1). The remaining students consisted of discordant pairs, since they indicated distinct cutoff points for each of the dentitions: $33(9.5 \%)$ students indicated 
that enamel should be restored in deciduous dentition lesions, but that in the permanent dentition the lesion would have to reach the dentine to characterize immediately required restorative treatment. The inverse option was indicated by 66 students and the difference between these groups was statistically significant (McNemar test: $\mathrm{p}=0.001$ ).

Overall, the results showed that restorative treatment in lesions extending up to the DEJ was proposed by $28.6 \%$ (99/346) of the final-year students for the deciduous dentition and by $38.2 \%(132 / 346)$ for the permanent dentition.

Table 2 shows that opting for treatment presented no difference between genders, in both the deciduous $(\mathrm{p}=0.429)$ and permanent dentitions $(\mathrm{p}=0.884)$; nor was there any difference for the student age groups concerning the decision for restorative treatment in the deciduous $(\mathrm{p}=0.602)$ and permanent dentitions $(\mathrm{p}=0.314)$.

Observation revealed a large variation in the criteria used to determine the need for restorative treatment between dental schools, both for the deciduous $(\mathrm{p}<0.001)$ and permanent dentitions $(\mathrm{p}<0.001)$. In lesions extending up to the DEJ in the deciduous dentition, there was one dental school in which no student $(0 \%)$ opted for restorative treatment, while in another school, $55.6 \%$ of the students indicated this option. In the permanent dentition, these frequencies varied between dental schools from $3 \%$ to $51.5 \%$.

Logistic regression analysis demonstrated that in the deciduous dentition, no statistically significant difference occurred in the restorative decision

Table 1 - Absolute and relative frequencies concerning the decision for restorative treatment in the deciduous and permanent dentitions by final-year dental students.

\begin{tabular}{|c|c|c|c|c|c|c|c|c|}
\hline & & \multicolumn{4}{|c|}{ Permanent teeth } & \multirow{2}{*}{\multicolumn{2}{|c|}{ Total }} & \multirow{3}{*}{$p^{*}$} \\
\hline & & \multicolumn{2}{|c|}{ Up to DEJ } & \multicolumn{2}{|c|}{ Dentine } & & & \\
\hline & & $n$ & (\%) & $n$ & $(\%)$ & $n$ & (\%) & \\
\hline \multirow{2}{*}{$\begin{array}{l}\text { Deciduous } \\
\text { teeth }\end{array}$} & Up to DEJ & 66 & $(19.1)$ & 33 & (9.5) & 99 & $(28.6)$ & \multirow{2}{*}{0.001} \\
\hline & Dentine & 66 & (19.1) & 181 & (52.3) & 247 & $(71.4)$ & \\
\hline \multicolumn{2}{|c|}{ Total } & 132 & (38.2) & 214 & (61.8) & & & \\
\hline
\end{tabular}

${ }^{*}$ McNemar test.

Table 2 - Absolute and relative frequencies concerning the decision for restorative treatment on the proximal surfaces of the deciduous and permanent dentitions by final-year dental students, according to gender.

\begin{tabular}{|c|c|c|c|c|c|c|c|c|c|c|}
\hline \multirow{3}{*}{ Gender } & \multicolumn{4}{|c|}{ Restorative criteria in deciduous teeth } & \multirow{3}{*}{$p^{*}$} & \multicolumn{4}{|c|}{ Restorative criteria in permanent teeth } & \multirow{3}{*}{$\mathrm{p}^{*}$} \\
\hline & \multicolumn{2}{|c|}{ Up to DEJ } & \multicolumn{2}{|c|}{ In dentine } & & \multicolumn{2}{|c|}{ Up to DEJ } & \multicolumn{2}{|c|}{ In dentine } & \\
\hline & $\mathrm{n}$ & $(\%)$ & $\mathrm{n}$ & (\%) & & $\mathrm{n}$ & $(\%)$ & $\mathrm{n}$ & (\%) & \\
\hline Male & 41 & $(31.1)$ & 91 & (68.9) & \multirow{2}{*}{0.429} & 51 & $(38.6)$ & 81 & (61.4) & \multirow{2}{*}{0.884} \\
\hline Female & 58 & $(27.1)$ & 156 & (72.9) & & 81 & $(37.9)$ & 133 & (62.1) & \\
\hline
\end{tabular}

${ }^{*}$ Chi-square test.

Table 3 - Absolute and relative frequencies, odds ratios (OR) and 95\% confidence intervals (95\% CI) regarding the decision for restorative treatment applied to the deciduous and permanent dentitions, according to the type of institution.

\begin{tabular}{|c|c|c|c|c|c|c|c|c|c|}
\hline \multirow{3}{*}{ Institution } & \multirow{3}{*}{ N } & \multicolumn{4}{|c|}{ Restorative criteria in deciduous teeth } & \multicolumn{4}{|c|}{ Restorative criteria in permanent teeth } \\
\hline & & \multicolumn{2}{|c|}{ Up to DEJ } & \multirow{2}{*}{ OR } & \multirow{2}{*}{$95 \% \mathrm{Cl}$} & \multicolumn{2}{|c|}{ Up to DEJ } & \multirow{2}{*}{ OR } & \multirow{2}{*}{$95 \% \mathrm{Cl}$} \\
\hline & & $n$ & $(\%)$ & & & $n$ & (\%) & & \\
\hline Private & 241 & 76 & $(31.5)$ & 1.64 & $(0.93-2.91)$ & 101 & $(41.9)$ & 1.72 & $(1.03-2.90)$ \\
\hline Public & 105 & 23 & $(21.9)$ & 1.00 & & 31 & $(29.5)$ & 1.00 & \\
\hline
\end{tabular}


criteria between public and private final-year dental students (Table 3). However, the probability of opting for restorative treatment in lesions extending up to the DEJ in the permanent dentition was $72 \%$ greater in students graduating from private dental schools in relation to public institutions (OR: 1.72; 95\% CI: $1.03-2.90)$.

\section{Discussion}

The application of a clinical simulation as an instrument to capture diagnostic and therapeutic decisions is frequently used in studies of this nature. Despite the subjectivity of the method, the standardization of a model and its replication in relation to the methodological design allows comparison between results obtained in different investigations. ${ }^{4,5,10,11}$ In certain studies, the use of a questionnaire seeks to base the findings on a gold standard. However, in the present study, the intention was not to compare the replies with a previously established standard, but rather to evaluate the therapeutic decision making of a final-year student population in the state of Rio Grande do Sul. Difficulties in determining coherent information in relation to diagnosis and therapeutic decision making have been previously reported. ${ }^{11,12}$ In the questionnaire applied here, the clinical profile of the patient was outlined, including information regarding patient age, $\mathrm{dmft}$ and DMFT, thus providing the student with information that would aid in the decision to indicate restorative treatment. The information of the radiographic exam was complemented by those indicators. ${ }^{13}$

The use of radiographic images for diagnosing proximal lesions in studies that analyzed the validity of the method is recognized as highly specific. Although sensitivity is compromised due to the amount of demineralized material required to produce a radiographic record, false-positive diagnoses appear not to compromise the performance of the method since the observation of a radiolucent image shows a strong correlation with demineralized tissue. The validity of the method, however, does not consolidate its use as an exclusive element of analysis in the therapeutic decision making process. ${ }^{3,14}$

Classification of a caries lesion, according to its penetration level, differs among the reports found in the related literature. In the present study, the penetration levels used followed a progressing lesion sequence: enamel, subdivided into external and internal, involvement of the dentino-enamel junction, and then the dentine, subdivided into external and internal involvement, for both the deciduous ${ }^{7}$ and permanent teeth. . $^{2,5,7,8,15}$

The indication for restorative treatment invariably entails the elimination of the dental structure affected. Although many of the students' responses only indicated the treatment of dentine lesions, therapeutic treatment for the enamel was indicated by a significant proportion of final-year students. Recent literature tends to consider the indication of immediate restorative treatment as adequate for dentine lesions. ${ }^{5,10,11}$ During the 1980 s, the criteria were different from those established in the 1990s. This fact was demonstrated by a group of researchers who compared the results of a questionnaire applied to Norwegian dentists on two different occasions, in 1983 and 1995. On the second occasion the dentists were shown to be more cautious regarding immediate restorative treatment in permanent teeth. In 1995, $81 \%$ of the professionals opted to indicate restorative treatment when the radiographic images showed that the lesion had already reached the dentine. ${ }^{8}$

The indication of immediate restorative treatment in dentine is mainly justified by the fact that the procedure should be limited to lesions that present clinical cavities and proven demineralization on the tooth surface. ${ }^{2}$ Restorative treatment by itself does not prevent or eliminate disease. However, this is apparently not the understanding of part of the population studied.

In light of current knowledge, the indication of restorative treatment in lesions strictly located on the enamel is considered excessive (overtreatment). With a lesion located on the external portion of the enamel, there is a high clinical probability that the lesion is a white stain of superficial integrity, both in deciduous ${ }^{3,7,14}$ and permanent teeth. ${ }^{2}$ Knowing that the caries disease process is dynamic and that the appearance of a lesion is the result of an imbalance, the importance of early diagnosis of an enamel lesion should be highlighted, not for restorative purposes, but for monitoring and control of the etio- 
logical factors involved, while seeking to reverse the caries process. In the majority of the teaching institutions evaluated, it would appear that this is not the understanding of the events surrounding this disease and its manifestations.

The indication of distinct restorative treatments for the deciduous and permanent dentitions was found in the present results, with fewer indications for immediate restorative treatment in deciduous teeth than in permanent teeth. Thus, the students proved to be more conservative in their approach to the deciduous dentition compared to the permanent dentition. Two possibilities could be inferred from this: either the students based their answers on aspects which are characteristic of the deciduous dentition (morphology) and the biological cycle of the same, or the students were unaware of the dynamic process of caries disease and, fearing its progression in the permanent teeth, indicated restorative treatment believing that this would stop it. In their study, Nuttall, Pitts ${ }^{15}$ (1990) showed that dentists also showed different attitudes in relation to the deciduous and permanent dentitions when questioned regarding diagnosis and the decision to indicate restorative treatment, mainly when considering lesions radiographically confined to the enamel. Concerning the indication of restorative treatment, a large variation between the dental schools regarding the criteria that define such treatment was observed, a fact also noted in research performed previously. ${ }^{4}$ The students' replies indicated a restorative approach for lesions located outside the dentine in both deciduous and permanent teeth. Notably, the probability of opting for restorative treatment in permanent dentition when the lesion was still restricted to the enamel was $72 \%$ greater among students attending

\section{References}

1. Araújo RM, Araújo MAM, Vannucci MG. Comprovação clínica de cáries interproximais diagnosticadas radiograficamente. Rev Odontol UNESP. 1998;27(2):553-65.

2. Bille J, Thylstrup A. Radiographic diagnosis and clinical tissue changes in relation to treatment of approximal carious lesions. Caries Res. 1982;16(1):1-6.

3. Feldens CA, Tovo MF, Kramer PF, Feldens EG, Ferreira SH, Finkler M. An in vitro study of the correlation between clinical private dental schools in relation to public institutions. Based on an initial analysis, one could infer from that that different philosophical differences in teaching exist between the private and public institutions. However, data that compare therapeutic approaches between private and public dental schools are inexistent in the related literature, and the results of this study do not contribute toward explaining the reasons for such differences.

Given the occurrence of large disparities in the results concerning therapeutic decision making, as revealed by the final-year students, we suggest ongoing analysis of the available clinical approaches to the caries disease process, so that academic training and education might include committed procedures regarding this theme.

\section{Conclusions}

The results of the present study permit the conclusion that a significant proportion of the final-year dental students indicated the restoration of proximal surfaces when the radiographic images of the lesions were still restricted to the enamel in both the deciduous and permanent dentitions; a lack of uniformity between the teaching institutions exists regarding the radiographic criteria that define the need for restorative treatment in such lesions; the option to proceed with a restorative treatment of the permanent teeth for lesions that are radiographically restricted to the enamel was greater among students graduating from private dental schools than those from public schools.

These data suggest that deep reflection is needed on the part of faculty regarding treatment approaches to the caries disease process in order to provide an evidence-based education.

and radiographic examinations of proximal carious lesions in primary molars. J Clin Pediatr Dent. 2003;27(2):143-8.

4. Maupomé G, Sheiham A. Radiographic criteria employed to diagnose and treat approximal caries by final-year dental students in Mexico City. Community Dent Oral Epidemiol. 1997;25(3):242-6. 
5. Maupomé G, Sheiham A. Decisions on diagnosis and management of approximal caries by final-year dental students. Dentomaxillofac Radiol. 1997;26(2):107-11.

6. Tveit AB, Espelid L, Skodje F. Restorative treatment decisions on approximal caries in Norway. Int Dent J. 1999;49(3):16572 .

7. Pitts NB, Rimmer PA. An in vivo comparison of radiographic and directly assessed clinical caries status of posterior approximal surfaces in primary and permanent teeth. Caries Res. 1992(2);26:146-52.

8. Thylstrup A, Fejerskov O. Diagnóstico radiológico no tratamento da cárie dentária. In: Thylstrup A, Fejerskov O. Cariologia Clínica. $2^{a}$ ed. São Paulo: Santos; 2001. p. 367-82.

9. Rothman KJ, Greenland S. Modern Epidemiology. Philadelphia: Lippincott-Williams \& Wilkins; 1998.

10. Lith A, Pettersson LG, Gröndahl HG. Radiographic study of approximal restorative treatment in children and adolescents in two Swedish communities differing in caries prevalence. Community Dent Oral Epidemiol. 1995;23(4):211-6.

11. Mejàre I, Sundberg H, Espelid I, Tveit B. Caries assessment and restorative treatment thresholds reported by Swedish dentists. Acta Odontol Scand. 1999;57(3):149-54.

12. Gabre P, Birring E, Gahnberg L. A 20 -year study of dentists' and dental hygienists' assessment of dental caries lesions in bite-wing radiographs. Swed Dent J. 2006;30(1):35-42.

13. Pitts NB. Regression of approximal carious lesion diagnosed from serial standardized bitewing radiographs. Caries Res. 1986;20(1):85-90.

14. Araújo FB, Araújo DR, Santos CK, Souza MA. Diagnosis of approximal caries in primary teeth: Radiographic versus clinical examination using tooth separation. Am J Dent. 1996;9(2):54-6.

15. Nuttall NM, Pitts NB. Restorative treatment thresholds reported to be used by dentists in Scotland. Br Dent J. 1990;169(5):119-26. 